\title{
Editors' preface: reviewing statistics and first evidence of impact
}

\author{
Nikos Nikiforakis ${ }^{1} \cdot$ Robert Slonim $^{2}$
}

Published online: 18 November 2016

(C) Economic Science Association 2016

\section{Introduction}

This issue marks 2 years since the Journal of the Economic Science Association (JESA) opened for submissions. We take this opportunity to share some summary statistics related to the reviewing process and some first evidence on the journal's impact. The latter indicates that JESA is off to a very promising start.

\section{Acceptance rate and reviewing process}

Table 1 presents information about the number of submissions and the percentage of submissions accepted in the first 2 years. As can be seen, during the first and second year, JESA received 80 and 76 submissions, respectively. For comparison, Experimental Economics (EXEC) received 80 submissions per annum for the first time in 2007 (Nikiforakis and Slonim 2015; Fig. 1), 9 years after its inaugural issue. Table 1 also shows that the acceptance rate in the past year was $15.0 \%$, down from $22.2 \%$ in the first year. This rate is similar to the acceptance rate at Experimental Economics in 2012 (Nikiforakis and Slonim 2015; Fig. 1).

Table 2 presents information on the speed of our review process. The average time until a first decision for all new submissions (i.e., accept, reject, revise and

\footnotetext{
Nikos Nikiforakis

nikos.nikiforakis@nyu.edu

Robert Slonim

robert.slonim@sydney.edu.au

1 New York University Abu Dhabi, Abu Dhabi, UAE

2 University of Sydney, Sydney, Australia
} 
Table 1 Submissions and acceptance rates

\begin{tabular}{lllc}
\hline & $\begin{array}{l}\text { Sept. 1, 2014-Aug. 31, } \\
\text { 2015 (year 1) }\end{array}$ & $\begin{array}{l}\text { Sept. 1, 2015-Aug. 31, } \\
\text { 2016 (year 2) }\end{array}$ & Overall \\
\hline $\begin{array}{l}\text { Number of new submissions } \\
\text { Number of submissions with }\end{array}$ & 80 & 76 & 156 \\
$\quad 58$ & 79 & 137 \\
$\quad \begin{array}{l}\text { Number of submissions with } \\
\quad \text { a final decision: accept }\end{array}$ & 12 & 12 & 24 \\
Acceptance rate & $22.2 \%$ & $15.2 \%$ & $17.5 \%$ \\
\hline
\end{tabular}

Table 2 Reviewing times

$\begin{array}{lcr}\begin{array}{l}\text { Sept. 1, 2014-Aug. 31, } \\ \text { 2015 (year 1) }\end{array} & \begin{array}{l}\text { Sept. 1, 2015-Aug. 31, } \\ \text { 2016 (year 2) }\end{array} & \text { Overall } \\ & & \\ 43.4 & 45.3 & 44.5 \\ 52.8 & 62.8 & 51.7 \\ & & \\ 54.6 & 86.2 & 72.8 \\ 88.5 & 121.3 & 95.3 \\ 132.8 & 250.9 & 191.8 \\ \end{array}$

resubmit) was 45.3 days, compared to 43.4 during the first year. If we exclude papers which were desk rejected, the average time until a first decision in the past year was 62.8 days, i.e., approximately 2 months. ${ }^{1}$

The average time for all papers with a final decision was 86.2, compared to 54.6 days in the first year. If we exclude papers which were desk rejected, the average time until a first decision in the past year was 121.3 days, i.e., approximately 4 months. Considering only papers that were accepted for publication, the average time from original submission to final acceptance rose from 132.6 days in the first year to 250.9 days in the past year. Although this is a substantial increase in time, the average time remains remarkably low (a bit over 8 months from submission to publication, including the time authors took to revise their manuscripts). ${ }^{2}$

Overall, these rates reflect the efficacy and dedication of many colleagues who accepted our invitation to review manuscripts, without whom it would have been impossible to keep decision times at these low levels.

\footnotetext{
${ }^{1}$ Of all submissions with a final decision, 23 (i.e., 39.7\%) were desk rejected in Year 1, and 22 (i.e., $27.8 \%$ ) in Year 2.

2 The low average during the first year was largely due to the very limited time we had to prepare the first issue. We believe the averages for this past year are more indicative of what authors should expect from JESA.
} 
Table 3 Google citations for articles published in the two ESA journals in the period July-December 2015 (JESA), and June-December 2015 (EXEC)

\begin{tabular}{lcc}
\hline & JESA & EXEC \\
\hline Average number of citations per article & 22.3 & 21.2 \\
Median number of citations per article & 6 & 7 \\
\hline
\end{tabular}

\section{First evidence of impact}

A very important metric for any journal is its impact. JESA will soon have its first official impact factor. However, we thought it would be useful to give readers a first sense of the journal's impact. We present aggregate data for the 15 articles published in the first two issues, as the third issue was published only 6 months ago, in July 2016.

The first issue of JESA was published in July 2015, approximately 16 months ago. The second issue was published a year ago, in December 2015. Although this is a short time period, according to Google Scholar, by October 26, 2016, the total number of Google cites was 334, implying an average citation index of 22.3 citations per article. A large number of citations are due to Greiner (2015); however, even if we exclude this article, the average number of citations per article is 8.1. The median number of citations using all articles is 6 .

Given our reliance on Google cites over a limited time period, it is useful to have a relevant reference point for comparison. We calculated the average and median number of Google citations for Experimental Economics (EXEC), for the three issues published in June, September and December 2015. ${ }^{3}$ Why compare with EXEC? Apart from being our companion journal, publishing papers that appeal firstly to experimental economists, EXEC has been a yardstick for JESA from the outset. As we wrote in the concluding section of our preface to JESA's inaugural issue (Nikiforakis and Slonim 2015), we "hope JESA will come to be regarded as highly as EXEC by scholars."

How does JESA fare? As can be seen in Table 3, JESA fares remarkably well. Both the average and median number of citations are similar to that in EXEC. This is remarkable given the limited time since JESA published its first issue. It certainly exceeded our expectations as editors.

\section{Concluding remarks}

The first evidence of impact and the low reviewing times indicate that JESA should be an attractive outlet for experimental economists to publish their work. Of course, the long-term success of the journal will continue to depend critically on the contributions of authors and the effort invested by reviewers.

\footnotetext{
${ }^{3}$ For the calculation, we excluded three errata that Experimental Economics published in December 2015 .
} 


\section{References}

Greiner, B. (2015). Subject pool recruitment procedures: organizing experiments with ORSEE. Journal of the Economic Science Association, 1(1), 2015, 114-125

Nikiforakis, N., \& Slonim, R. (2015). Editor's Preface: introducing JESA. Journal of the Economic Science Association, 1(1), 1-7. 